Check for updates

Cite this: RSC Adv., 2021, 11, 4966

Received 14th January 2021

Accepted 20th January 2021

DOI: $10.1039 / \mathrm{d} 1 \mathrm{ra00324k}$

rsc.li/rsc-advances

\section{Metal-free synthesis of 1,4-benzodiazepines and quinazolinones from hexafluoroisopropyl 2- aminobenzoates at room temperature $\uparrow$}

\author{
Jiewen Chen, $\$$ En Liang, $\$$ Jie Shi, ${ }^{*}$ Yinrong Wu, Kangmei Wen, Xingang Yao \\ and Xiaodong Tang (D)*
}

Herein, we describe the novel reactivity of hexafluoroisopropyl 2-aminobenzoates. The metal-free synthesis of 1,4-benzodiazepines and quinazolinones from hexafluoroisopropyl 2-aminobenzoates has been developed at room temperature. These procedures feature good functional group tolerance, mild reaction conditions, and excellent yields. The newly formed products can readily be converted to other useful N-heterocycles. Moreover, the products and their derivatives showed potent anticancer activities in vitro by MTT assay.
Benzodiazepines (BDZs), especially 1,4-benzodiazepines, are privileged motifs in pharmaceuticals. ${ }^{1}$ For examples, oxazepam is used to treat anxiety disorders or alcohol withdrawal symptoms; triazolam is used to treat insomnia (Scheme 1). Until now, some synthetic approaches to 1,4-benzodiazepine skeletons have been developed include isocyanide-based multicomponent reactions, ${ }^{2}$ cycloadditions, ${ }^{3}$ metal-catalyzed tandem reactions, ${ }^{4}$ and redox-neutral $[5+2]$ annulation with $o$ aminobenzaldehydes. ${ }^{5}$ However, these procedures have some limitations involving unavailable materials, several steps, harsh reaction conditions and low yields. $\alpha$-Haloamides are widely used to synthesize N-heterocycles. ${ }^{6}$ Recently, some groups reported the synthesis of 1,4-benzodiazepines with $\alpha$-haloamides. ${ }^{7}$ Kim and coworkers developed a [4+3]-annulation reaction between $\alpha$-haloamides and isatoic anhydrides for 1,4benzodiazepines, but the reaction required $80{ }^{\circ} \mathrm{C}$ reaction temperature and provided an unsatisfactory yield. ${ }^{a}{ }^{a}$ Singh's group reported a two-step method to construct 1,4-benzodiazepines from $\alpha$-haloamides and anthranils, but the anthranils are not readily available substrates and the second step also required $80{ }^{\circ} \mathrm{C}$ reaction temperature. ${ }^{7 b}$ Quinazolinones are a significant class of heterocycles that widely occur in natural products and pharmaceuticals (Scheme 1). ${ }^{8}$ These compounds exhibit a range of biological activities including anticancer, antibacterial, antiinflammatory, antifungal, etc. Due to their

Guangdong Provincial Key Laboratory of New Drug Screening, School of Pharmaceutical Sciences, Southern Medical University, 1023 South Shatai Road, Baiyun District, Guangzhou 510515, P. R. China. E-mail: shijie7542@163.com; tangxdong@smu.edu.cn

$\dagger$ Electronic supplementary information (ESI) available: Experimental section, characterization of all compounds, copies of ${ }^{1} \mathrm{H}$ and ${ }^{13} \mathrm{C}$ NMR spectra for all target compounds. See DOI: 10.1039/d1ra00324k

$\$$ These authors contributed equally to this work. significant value, the synthesis of quinazolinones has attracted considerable attention. The reported synthetic methods can be summarized as: (i) condensation of 2-aminobenzamides with carbonyl compounds; ;ii) oxidative cyclization of primary alcohols with 2 -aminobenzamides or 2 -aminobenzonitriles; ${ }^{10}$ (iii) metal-catalyzed coupling/cyclization reactions; ${ }^{11}$ and (iv) palladium-catalyzed carbonylation reactions. ${ }^{12}$ But these synthetic methods also had some disadvantages. Thus, it is highly desirable to develop new available reagents for synthesizing the useful $\mathrm{N}$-heterocycles such as benzodiazepines and quinazolinones with good yields under mild reaction conditions.

In the past few years, 2-aminobenzoates have been used for the synthesis of $\mathrm{N}$-heterocycles via $[4+n]$ cyclization (Scheme 2a). ${ }^{13}$ However, harsh reaction conditions such as high reaction temperatures and strong bases or acids were required to effect alkoxy leaving. When we tried to synthesize benzodiazepines or quinazolinones with methyl or tert-butyl 2-aminobenzoates, we<smiles>O=C1Nc2ccc(Cl)cc2C(c2ccccc2)=NC1O</smiles><smiles>Cc1ccccc1-n1c(C)nc2ccccc2c1=O</smiles>

Methaqualone<smiles>Cc1nnc2n1-c1ccc(Cl)cc1C(c1ccccc1Cl)=NC2</smiles><smiles>CCCCCCCCCCCC(O)Cn1c(C)nc2ccccc2c1=O</smiles>

Scheme 1 Structures of representative 1,4-benzodiazepine and quinazolinone drugs. 


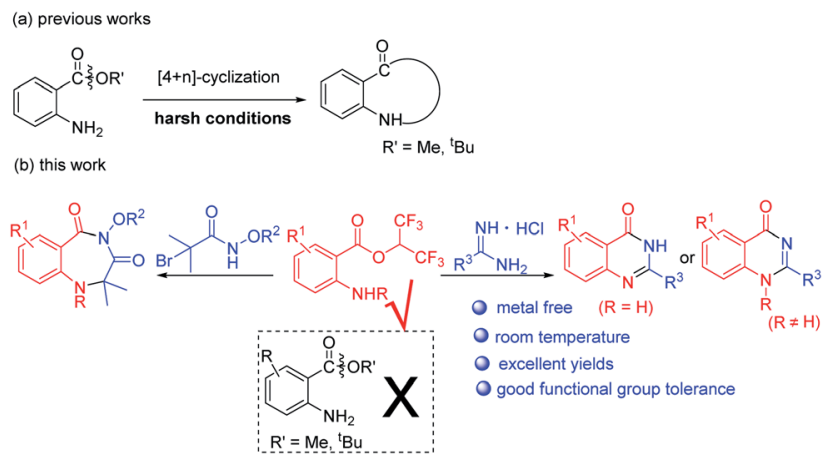

Scheme 2 Synthesis of $\mathrm{N}$-heterocycles from 2-aminobenzoates.

Table 1 Optimization of reaction conditions ${ }^{a}$

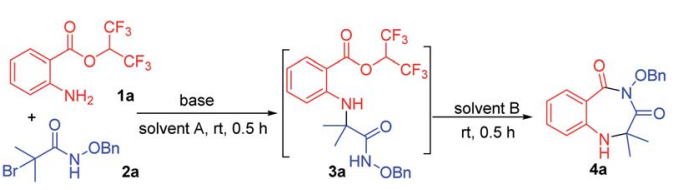

\begin{tabular}{lllll}
\hline Entry & Base & Solvent A & Solvent B & Yield (\%) \\
\hline 1 & $\mathrm{Et}_{3} \mathrm{~N}$ & HFIP & DMF & 68 \\
2 & $\mathrm{Cs}_{2} \mathrm{CO}_{3}$ & HFIP & DMF & 97 \\
3 & $\mathrm{NaHCO}_{3}$ & HFIP & DMF & n.d. \\
4 & $\mathrm{~K}_{2} \mathrm{CO}_{3}$ & HFIP & DMF & n.d. \\
5 & DBU & HFIP & DMF & 61 \\
6 & $\mathrm{NaOH}$ & HFIP & DMF & 93 \\
7 & DIPEA & HFIP & DMF & 63 \\
8 & - & HFIP & DMF & 0 \\
9 & $\mathrm{Cs}_{2} \mathrm{CO}_{3}$ & DMSO & - & 0 \\
10 & $\mathrm{Cs}_{2} \mathrm{CO}_{3}$ & DMA & - & 0 \\
11 & $\mathrm{Cs}_{2} \mathrm{CO}_{3}$ & MeCN & - & 0 \\
12 & $\mathrm{Cs}_{2} \mathrm{CO}_{3}$ & Toluene & - & 0 \\
13 & $\mathrm{Cs}_{2} \mathrm{CO}_{3}$ & HFIP & DMA & 71 \\
14 & $\mathrm{Cs}_{2} \mathrm{CO}_{3}$ & HFIP & DMSO & 41 \\
15 & $\mathrm{Cs}_{2} \mathrm{CO}_{3}$ & HFIP & MeCN & 40 \\
16 & $\mathrm{Cs}_{2} \mathrm{CO}_{3}$ & HFIP & Dioxane & 38 \\
17 & $\mathrm{Cs}_{2} \mathrm{CO}_{3}$ & HFIP & NMP & n.d. \\
18 & $\mathrm{Cs}_{2} \mathrm{CO}_{3}$ & HFIP & Toluene & n.d. \\
$19^{b}$ & $\mathrm{Cs}_{2} \mathrm{CO}_{3}$ & HFIP & DMF & 92
\end{tabular}

${ }^{a}$ Reaction conditions: unless otherwise noted, all reactions were performed with $1 \mathrm{a}(0.3 \mathrm{mmol}), 2 \mathrm{a}(0.3 \mathrm{mmol})$, and base $(0.3 \mathrm{mmol})$ in solvent A $(3.0 \mathrm{~mL})$ at room temperature for $0.5 \mathrm{~h}$, then the solvent $\mathrm{A}$ was removed under vacuum and solvent $\mathrm{B}(2.0 \mathrm{~mL})$ added to react for 0.5 h. Isolated yield. ${ }^{b}$ Yield on a $3.0 \mathrm{mmol}$ scale.

failed. Recently, hexafluoroisopropanol (HFIP) has attracted a lot of attention when used as solvent or substrate, due to its special properties. ${ }^{14}$ When we used isatoic anhydrides as substrates and $\mathrm{NEt}_{3}$ as base in HFIP at room temperature, we unexpectedly discovered that hexafluoroisopropyl 2-aminobenzoates were completely formed. We supposed hexafluoroisopropyl 2-aminobenzoates were good synthons for the synthesis of $\mathrm{N}$-heterocycles. Herein, we report metal-free procedures for the synthesis of 1,4-benzodiazepines and quinazolinones from hexafluoroisopropyl 2-aminobenzoates at room temperature with excellent yields (Scheme $2 \mathrm{~b}$ ).
Table 2 Substrate scope for the synthesis of 1,4-benzodiazepines ${ }^{a}$

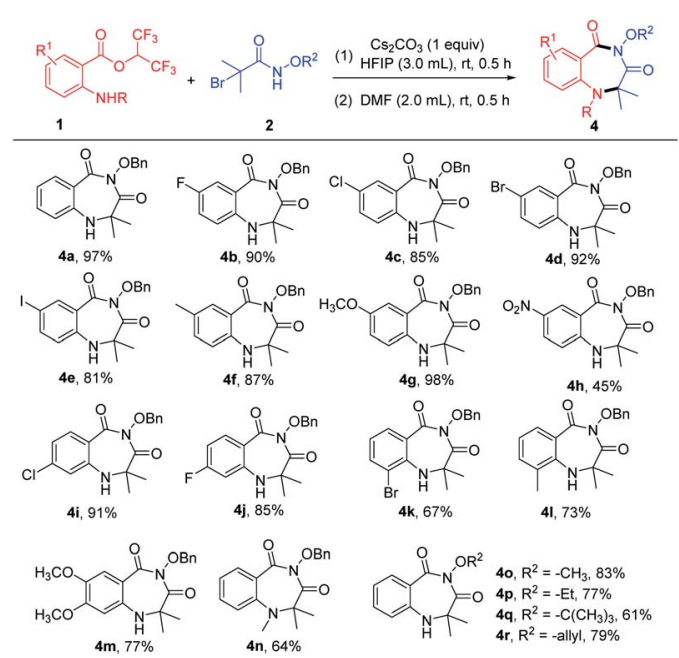

${ }^{a}$ Reaction conditions: $1(0.3 \mathrm{mmol}), 2(0.3 \mathrm{mmol})$, and $\mathrm{Cs}_{2} \mathrm{CO}_{3}(0.3$ $\mathrm{mmol})$ in solvent HFIP $(3.0 \mathrm{~mL})$ at room temperature for $0.5 \mathrm{~h}$, then the HFIP was removed under vacuum and added DMF $(2.0 \mathrm{~mL})$ to continue to react for $0.5 \mathrm{~h}$. Isolated yield.

Table 3 Substrate scope for the synthesis of quinazolinones ${ }^{a}$

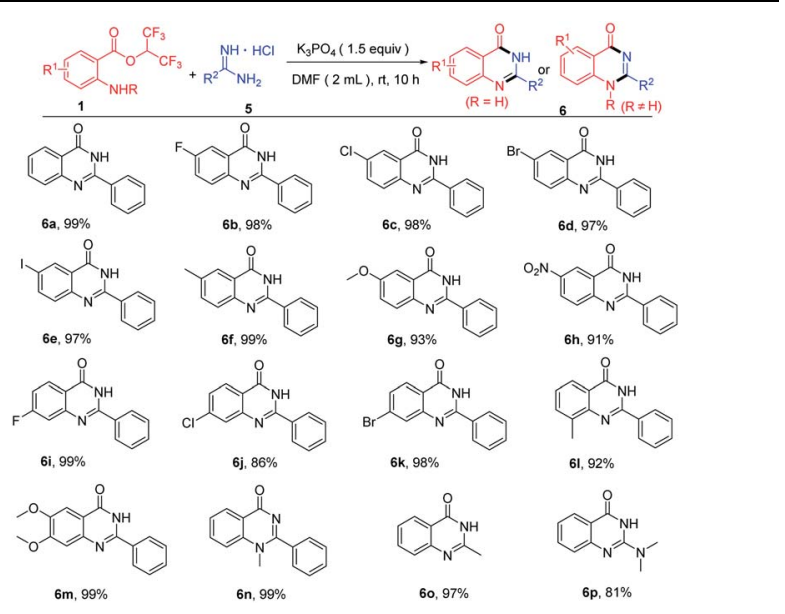

${ }^{a}$ Reaction conditions: $\mathbf{1}(0.3 \mathrm{mmol}), \mathbf{5}(0.36 \mathrm{mmol}), \mathrm{K}_{3} \mathrm{PO}_{4}(0.45 \mathrm{mmol})$, DMF $(2.0 \mathrm{~mL})$ at room temperature for $10 \mathrm{~h}$. Isolated yields.

We examined the annulation reaction with hexafluoroisopropyl 2-aminobenzoate (1a) and $\boldsymbol{\alpha}$-bromoamide (2a) as the model substrates. Initially, when the reaction was performed with 1 equiv. of $\mathrm{Et}_{3} \mathrm{~N}$ in HFIP at room temperature for $0.5 \mathrm{~h}$, 3a was formed, but cyclization product 4 a was not obtained. We thought the transformation from $3 a$ to the product 4a needing to release one molecule of HFIP, and the transformation maybe be inhibited when HFIP was used as solvent. So we removed the solvent HFIP under vacuum and added $2.0 \mathrm{~mL}$ DMF to react for $0.5 \mathrm{~h}$. Pleasingly, the desired product $4 \mathrm{a}$ 
was obtained in $68 \%$ yield (Table 1 , entry 1 ). Then, a series of bases were checked, and $\mathrm{Cs}_{2} \mathrm{CO}_{3}$ seemed to be the best choice (Table 1, entries 2-7). When using $\mathrm{NaHCO}_{3}$ and $\mathrm{K}_{2} \mathrm{CO}_{3}$ as bases, 3a was obtained, but it cannot be converted to the product 4 a. The reaction cannot take place without base (Table 1, entry 8). When we replaced the HFIP with another solvent (DMSO, DMA, MeCN, toluene), the reaction cannot occur (Table 1, entries 912). The transformation from $3 \mathbf{a}$ to product $4 \mathbf{a}$ with different solvents was also investigated; the results showed that other solvents, such as DMA, DMSO, MeCN and dioxane, NMP, toluene, were less effective (Table 1, entries 13-16) or ineffective (Table 1, entries 17 and 18). A gram-scale reaction was performed to give product $\mathbf{4 a}$ in $92 \%$ yield (Table 1, entry 19). We also tried to use a mixture of HFIP and other solvent in order to directly form the desired cyclic compound in a one-pot manner, but the yields was low.

After determining the optimized reaction conditions, the scope of the cyclization reaction for 1,4-benzodiazepines was examined (Table 2). Various 5-substituted 2-aminobenzoates bearing halo groups ( $\mathrm{F}, \mathrm{Cl}, \mathrm{Br}, \mathrm{I})$ and electron-donating groups $\left(\mathrm{CH}_{3}, \mathrm{OCH}_{3}\right)$ smoothly underwent cyclization reaction to furnish desired products in good to excellent yields (Table 2, 4b-4g). The nitro group was tolerated in the transformation, but the yield was low (Table 2 and $\mathbf{4 h}$ ). The reactions also proceeded in the case of 4-substituted 2-aminobenzoates with high yields (Table 2, 4i-4j). When 3-substituted 2-aminobenzoates were employed as substrates, the yields were relatively low because the steric hindrance was unfavorable in intramolecular nucleophilic attack (Table 2, 4k-4l). Furthermore, 4,5-dimethoxy 2aminobenzoate and 2-(methylamino)benzoate afforded the expected products $4 \mathrm{~m}$ and $4 \mathrm{n}$ in $77 \%$ and $64 \%$ yields, respectively. In addition, $\alpha$-bromoamides with diverse $N$-protecting groups $\left(-\mathrm{OCH}_{3},-\mathrm{OEt},-\mathrm{O}^{t} \mathrm{Bu},-\right.$ allyloxy$)$ showed good compatibility,
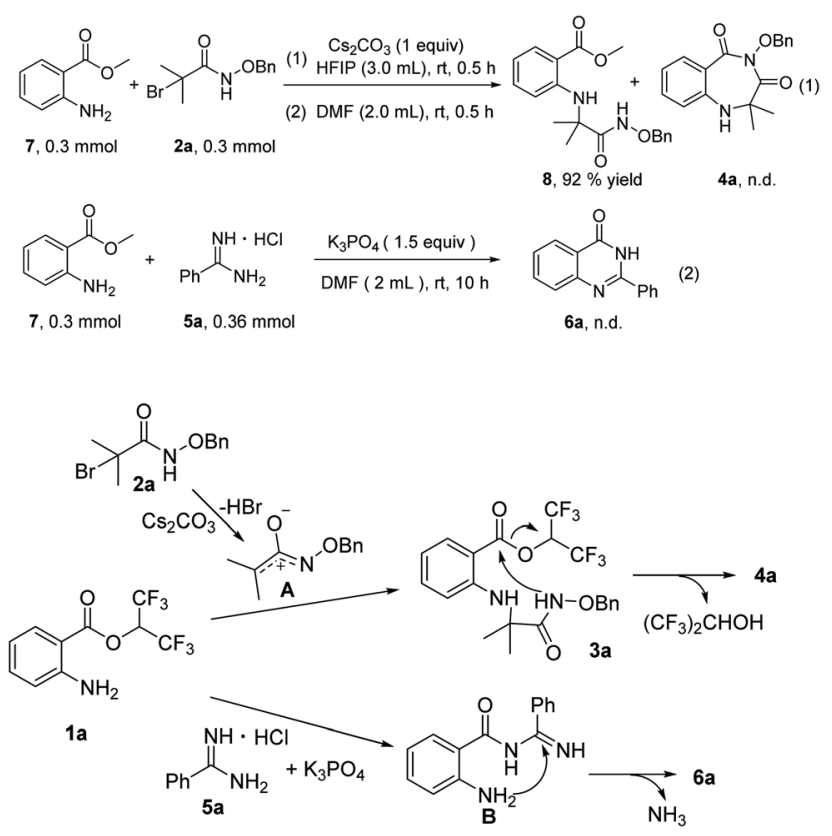

Scheme 3 Control experiments and possible reaction mechanism.

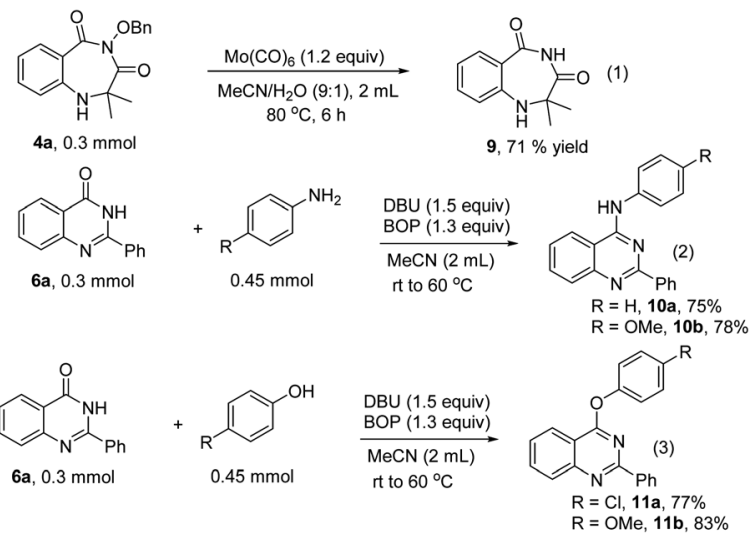

Scheme 4 Derivatization of products.

delivering the corresponding products in 61-83\% yields (Table 2, 4o-4r). Unfortunately, mono-substituted $\alpha$-bromohydroxamates, unsubstituted $\alpha$-bromohydroxamates, and $N$-alkylated bromoacetamides did not react under the current reaction conditions.

When hexafluoroisopropyl 2-aminobenzoates reacted with amidines hydrochloride in the presence of base, quinazolinones were produced. Then, we optimized the reaction conditions to enhance the yields of the quinazolinones (see the $\mathrm{ESI}^{\dagger}$ for more details). With optimum conditions in hand, substrate scope for the synthesis of quinazolinones was next investigated (Table 3). Hexafluoroisopropyl 2-aminobenzoates bearing diverse groups at the amino para-position, including $\mathrm{F}, \mathrm{Cl}, \mathrm{Br}, \mathrm{I}$, $\mathrm{CH}_{3}, \mathrm{OCH}_{3}$ and $\mathrm{NO}_{2}$ were all compatible with this procedure to afford the cyclization products in excellent yields (Table $3, \mathbf{6 b}-$ 6h). In addition, various 4-substituted, 3-substituted and 4,5disubstituted 2-aminobenzoates reacted well with benzamidine hydrochloride, and the corresponding product yields ranged $86 \%$ to $99 \%$ (Table $3, \mathbf{6 i - 6 m}$ ). Notably, methyl protected 2aminobenzoates were also transformed to the product $\mathbf{6 n}$ in 99\% yield. To our delight, this protocol was also applied to acetamidine hydrochloride and 1,1-dimethylguanidine hydrochloride affording the target products in $97 \%$ and $81 \%$, respectively (Table 3, 6o-6p).

Table 4 Biological applications

\begin{tabular}{llll}
\hline & $\mathrm{IC}_{50}(\mu \mathrm{M})$ & & \\
\cline { 2 - 4 } Compounds & $\mathrm{A} 549$ & $\mathrm{HCT} 116$ & $\mathrm{MCF} 7$ \\
\hline $\mathbf{4 e}$ & $64.69 \pm 7.35$ & $33.27 \pm 5.84$ & $40.32 \pm 0.49$ \\
$\mathbf{6 c}$ & $35.11 \pm 3.40$ & $26.61 \pm 1.26$ & $58.12 \pm 3.45$ \\
$\mathbf{6 d}$ & $52.32 \pm 2.85$ & $23.58 \pm 1.50$ & $81.32 \pm 2.80$ \\
$\mathbf{6 f}$ & $82.89 \pm 10.34$ & $59.59 \pm 1.60$ & $38.52 \pm 1.83$ \\
$\mathbf{6 g}$ & $67.00 \pm 8.24$ & $32.90 \pm 0.60$ & $42.54 \pm 3.79$ \\
$\mathbf{6 1}$ & $19.56 \pm 1.16$ & $17.73 \pm 2.32$ & $25.00 \pm 5.30$ \\
$\mathbf{1 0 a}$ & $14.79 \pm 1.15$ & $26.31 \pm 3.95$ & $29.70 \pm 0.09$ \\
$\mathbf{1 0 b}$ & $5.98 \pm 0.42$ & $15.41 \pm 4.41$ & $21.12 \pm 1.06$ \\
$\mathbf{1 1 a}$ & $68.54 \pm 3.70$ & $17.84 \pm 3.13$ & $75.84 \pm 2.50$ \\
$\mathbf{1 1 b}$ & $94.76 \pm 1.14$ & $25.14 \pm 5.31$ & $67.13 \pm 3.65$ \\
5-Fu & $>100$ & $13.03 \pm 2.80$ & $29.58 \pm 12.86$
\end{tabular}


To probe the reaction mechanism, several preliminary experiments were conducted (Scheme 3 ). Under standard reaction conditions, methyl 2-aminobenzoates 7 reacted with 2 a to provide compound 8 in $92 \%$ yield, and 4 a was not detected. This control experiment indicated the importance of hexafluoroisopropyl (Scheme 3, eqn (1)). Treatment of methyl 2aminobenzoates 7 with $5 \mathbf{a}$ in the presence of $\mathrm{K}_{3} \mathrm{PO}_{4}$ did not furnish any product 6a, and 3a did not convert at all (Scheme 3, eqn (2)). On the basis of the control experiments and previous reports, we propose a possible mechanism. First, aza-oxyallyl cation $\mathbf{A}$ is formed from $\alpha$-bromoamide with $\mathrm{Cs}_{2} \mathrm{CO}_{3} \cdot{ }^{15}$ Whereafter, aza-oxyallyl cation A combines with 1a to produce compound 3a. ${ }^{15 b}$ The product $\mathbf{4 a}$ is obtained via intramolecular nucleophilic substitution, releasing a molecule of hexafluoroisopropanol. The nucleophilic attack of $5 \mathbf{a}$ onto 1a provides the intermediate $\mathbf{B}$. Subsequently, product $\mathbf{6 a}$ is formed by intramolecular nucleophilic addition/deamination cyclization.

In order to address the potential synthetic application of our methods, the transformations of the obtained 1,4-benzodiazepines and quinazolinones were performed (Scheme 4). Compound 9 was formed from 4 a through cleavage of the $\mathrm{N}-\mathrm{O}$ bond with $\mathrm{Mo}(\mathrm{CO})_{6}$ (Scheme 4, eqn (1)). The quinazolinones can be transformed into substituted quinazolines with anilines or phenols as nucleophilic reagents in the presence of BOP and DBU (Scheme 4, eqn (2) and (3)).

We next investigated the cytotoxicity of the products and their derivatives against cancer cell lines (A549, HCT116 and MCF7) by MTT assay, with 5-fluorouracil (5-FU) as the positive control. To our delight, some products and their derivatives exhibited potent inhibitory activities, and some of them showed better inhibitory activities than 5-Fu (Table 4). These results revealed that our methods had potential applications in discovering new lead compounds with anti-tumor activities.

In summary, we have developed novel and simple approaches for the synthesis of 1,4-benzodiazepines and quinazolinones from hexafluoroisopropyl 2-aminobenzoates with $\alpha$-bromoamides or amidines hydrochloride. These protocols feature readily available starting materials, mild reaction conditions, good functional group tolerance, and excellent yields. In addition, the newly obtained products and their derivatives showed potent anticancer activities in vitro by MTT assay. Further studies on the synthesis of other N-heterocycles from hexafluoroisopropyl 2-aminobenzoates are in progress.

\section{Conflicts of interest}

There are no conflicts to declare.

\section{Acknowledgements}

This work was supported by the National Natural Science Foundation of China (21702096), and the High-level Talent Introduction Foundation of Southern Medical University (C1033520) for financial support.

\section{Notes and references}

1 (a) A. C. Araújo, A. P. Rauter, F. Nicotra, C. Airoldi, Ba. Costa and L. Cipolla, J. Med. Chem., 2011, 54, 1266; (b) A. K. Shah, J. Bariwal, S. Bansal, J. Chugh and J. B. Bariwal, Chem. Biol. Interface, 2012, 2, 12; (c) R. Siegrist, D. Pozzi, G. Jacob, C. Torrisi, K. Colas, B. Braibant, J. Mawet, T. Pfeifer, R. Kanter, C. Roch, M. Kessler, O. Corminboeuf and O. Bezencon, J. Med. Chem., 2016, 59, 10661; (d) M. M. Poe, K. R. Methuku, G. Li, A. R. Verma, K. A. Teske, D. C. Stafford, L. A. Arnold, J. W. Cramer, T. M. Jones, R. Cerne, M. J. Krambis, J. M. Witkin, E. Jambrina, S. Rehman, M. Ernst, J. M. Cook and J. M. Schkeryantz, J. Med. Chem., 2016, 59, 10800; (e) R. Ettari, S. Previti, S. Cosconati, S. Maiorana, T. Schirmeister, S. Grasso and M. Zappalà, Bioorg. Med. Chem. Lett., 2016, 26, 3453.

2 (a) R. S. Borisov, A. I. Polyakov, L. A. Medvedeva, V. N. Khrustalev, N. I. Guranova and L. G. Voskressensky, Org. Lett., 2010, 12, 3894; (b) Y. Wang, M. Chen and M.-W. Ding, Tetrahedron, 2013, 69, 9056; (c) H. Xie, J.-C. Liu and M.-W. Ding, Synthesis, 2016, 48, 4541; (d) Y. Huang, K. Khoury, T. Chanas and A. Dömling, Org. Lett., 2012, 14, 5916.

3 (a) K. G. Guggenheim, H. Toru and M. J. Kurth, Org. Lett., 2012, 14, 3732; (b) C. S. Chambers, N. Patel and K. Hemming, Tetrahedron Lett., 2010, 51, 4859; (c) K. C. Majumdar and S. Ganai, Tetrahedron Lett., 2013, 54, 6192; (d) J. Shin, J. Lee, D. Ko, N. De and E. J. Yoo, Org. Lett., 2017, 19, 2901; (e) J. Feng, M. Zhou, X. Lin, A. Lu, X. Zhang and M. Zhao, Org. Lett., 2019, 21, 6245.

4 (a) P. Kundu, A. Mondal, B. Das and C. Chowdhury, Adv. Synth. Catal., 2015, 357, 3737; (b) V. Murugesh, B. Harish, M. Adiseshu, J. B. Nanubolu and S. Suresh, Adv. Synth. Catal., 2016, 358, 1309; (c) J. D. Neukom, A. S. Aquino and J. P. Wolfe, Org. Lett., 2011, 13, 2196; (d) L. P. Tardibono and J. M. J. Miller, Org. Lett., 2009, 11, 1575.

5 (a) S. Wang, Y.-B. Shen, L.-F. Li, B. Qiu, L. Yu, Q. Liu and J. Xiao, Org. Lett., 2019, 21, 8904; (b) S. Liu, T. Zhao, J. Qu and B. Wang, Adv. Synth. Catal., 2018, 360, 4094.

6 (a) A. Fantinati, V. Zanirato, P. Marchetti and C. Trapella, ChemistryOpen, 2020, 9, 100; (b) A. E. Bouakher, A. Martel and S. Comesse, Org. Biomol. Chem., 2019, 17, 8467; (c) J. Xuan, X. Cao and X. Cheng, Chem. Commun., 2018, 54, 5154.

7 (a) E. Kim, C. Y. Lee and S.-G. Kim, Adv. Synth. Catal., 2020, 362, 3594; (b) A. J. Ansari, A. Yadav, A. Mukherjee, E. Sathish, K. Nagesh and R. Singh, Chem. Commun., 2020, 56, 4804.

8 (a) H.-P. Buchstaller, U. Anlauf, D. Dorsch, D. Kuhn, M. Lehmann, B. Leuthner, D. Musil, D. Radtki, C. Ritzert, F. Rohdich, R. Schneider and C. Esdar, J. Med. Chem., 2019, 62, 7897; (b) S. Gatadi, T. V. Lakshmi and S. Nanduri, Eur. J. Med. Chem., 2019, 170, 157; (c) E. Pitta, O. Balabon, M. K. Rogacki, J. Gómez, F. Cunningham, J. Joosens, K. Augustyns, P. Veken and R. Bates, Eur. J. Med. Chem., 2017, 125, 890; (d) C.-W. Yu, P.-T. Chang, L.-W. Hsin and J.-W. Chern, J. Med. Chem., 2013, 56, 6775; (e) F. Rörsch, 
E. Buscató, K. Deckmann, G. Schneider, M. SchubertZsilavecz, G. Geisslinger, E. Proschak and S. Grösch, J. Med. Chem., 2012, 55, 3792.

9 (a) F. Li, L. Lua and J. Ma, Org. Chem. Front., 2015, 2, 1589; (b) L. Cao, H. Huo, H. Zeng, Y. Yu, D. Lu and Y. Gong, Adv. Synth. Catal., 2018, 360, 4764; (c) S. Mohammed, R. A. Vishwakarma and S. B. Bharate, J. Org. Chem., 2015, 80, 6915.

10 (a) J. Zhou and J. Fang, J. Org. Chem., 2011, 76, 7730; (b) Z. Zhang, M. Wang, C. Zhang, Z. Zhang, J. Lu and F. Wang, Chem. Commun., 2015, 51, 9205; (c) A. J. A. Watson, A. C. Maxwell and J. M. J. Williams, Org. Biomol. Chem., 2012, 10, 240; (d) K. Upadhyaya, R. K. Thakur, S. K. Shukla and R. P. Tripathi, J. Org. Chem., 2016, 81, 5046; (e) S. Parua, S. Das, R. Sikari, S. Sinha and N. D. Paul, J. Org. Chem., 2017, 82, 7165; (f) S. Das, S. Sinha, D. Samanta, R. Mondal, G. Chakraborty, P. Brandaõ and N. D. Paul, J. Org. Chem., 2019, 84, 10160; (g) Y. Hu, S. Li, H. Li, Y. Li, J. Li, C. Duanmu and B. Li, Org. Chem. Front., 2019, 6, 2744; (h) H. Hikawa, Y. Ino, H. Suzuki and Y. Yokoyama, J. Org. Chem., 2012, 77, 7046.

11 (a) D. Yang, H. Fu, L. Hu, Y. Jiang and Y. Zhao, J. Comb. Chem., 2009, 11, 653; (b) W. Xu and H. Fu, J. Org. Chem., 2011, 76, 3846; (c) X. Zhang, D. Ye, H. Sun, D. Guo, J. Wang, H. Huang, X. Zhang, H. Jianga and H. Liu, Green Chem., 2009, 11, 1881.

12 (a) B. Ma, Y. Wang, J. Peng and Q. Zhu, J. Org. Chem., 2011, 76, 6362; (b) X.-F. Wu, L. He, H. Neumann and M. Beller, Chem.-Eur. J., 2013, 19, 12635; (c) H. Li, L. He,
H. Neumann, M. Beller and X.-F. Wu, Green Chem., 2014, 16, 1336; (d) J. Chen, K. Natte, H. Neumann and X.-F. Wu, Chem.-Eur. J., 2014, 20, 16107.

13 (a) J. Lei, G.-T. Song, Y.-F. Luo, D.-Y. Tang, W. Yan, H.-Y. Li, Z.-Z. Chen and Z.-G. Xu, Org. Chem. Front., 2020, 7, 737; (b) R. V. Gadhave and B. S. Kuchekar, Asian J. Chem., 2020, 32, 580; (c) A. V. Bogolubsky, S. V. Ryabukhin, A. S. Plaskon, S. V. Stetsenko, D. M. Volochnyuk and A. A. Tolmachev, J. Comb. Chem., 2008, 10, 858; (d) Y. Chi, L. Xu, S. Du, H. Yan, W.-X. Zhang and Z. Xi, Chem.-Eur. J., 2015, 21, 10369; (e) S. Kang, S. Park, K.-S. Kim, C. Song and Y. Lee, J. Org. Chem., 2018, 83, 2694; (f) C. Lu, C. Gong, B. Zhao, L. Hu and Y. Yao, J. Org. Chem., 2018, 83, 1154; $(g)$ S. R. Narra, S. Avula, R. R. Kuchukulla, J. B. Nanubolu, N. Banda and R. Yadla, Tetrahedron, 2017, 73, 4730.

14 (a) W. Wang, X. Cao, W. Xiao, X. Shi, X. Zuo, L. Liu, W. Chang and J. Li, J. Org. Chem., 2020, 85, 7045; (b) J. Chen, M. Li, J. Zhang, W. Sun and Y. Jiang, Org. Lett., 2020, 22, 3033; (c) M. A. Boichenko, I. A. Andreev, A. O. Chagarovskiy, I. I. Levina, S. S. Zhokhov, I. V. Trushkov and O. A. Ivanova, J. Org. Chem., 2020, 85, 1146; (d) A. Roth and S. E. Denmark, J. Am. Chem. Soc., 2019, 141, 13767; (e) Z.-K. Wen, X.-M. Ge, Z.-K. Zhao and J.-B. Chao, Adv. Synth. Catal., 2019, 361, 983.

15 (a) A. Acharya, K. Montes and C. S. Jeffrey, Org. Lett., 2016, 18, 6082; (b) T. Bera, B. Singh, T. A. Hamlin, S. C. Sahoo and J. Saha, J. Org. Chem., 2019, 84, 15255. 